\title{
Do mass deworming efforts improve the developmental health and well- being of children in low-and middle-income countries? Summary of the evidence and implications for public health programmes
}

\author{
Denny John ${ }^{\mathrm{a}, \mathrm{b}, *}$, Anns Issac ${ }^{\mathrm{c}}$ \\ a Campbell Collaboration, New Delhi, India \\ b ICMR-National Institute of Medical Statistics (NIMS), New Delhi, India \\ ${ }^{\mathrm{c}}$ Independent Researcher, New Delhi, India
}

A R T I C L E I N F O

\section{Keywords:}

Systematic review

Mass deworming

Child development

Low and middle-income countries

\begin{abstract}
A B S T R A C T
Objective: This evidence summary of a Campbell systematic review evaluated the effectiveness of mass deworming for soil transmitted helminthes with or without deworming for schistosomiasis or co-interventions on growth, educational achievement, cognition, school attendance, quality of life and adverse effects in children from randomized trials, quasi-randomized trials, controlled before after studies, interrupted time series and quasi-experimental studies.

Methods: Summary of evidence was prepared using standard methods for conducting and reporting evidence summary and using SUPPORT summary format.

Results: The Campbell review included data from 66 studies covering 1,092,120 children (6 months-16 years) in high, medium, and low helminthes-endemic areas from 23 low and middle-income countries. As compared to previous reviews on the topic, the different conclusions of current review are due to inclusion of more studies and adoption of a strict criterion for the certainty of evidence.

Conclusion: The review found that mass deworming for soil transmitted helminthes had little to no effect on child health and other well-being measures.
\end{abstract}

\section{Introduction: the evidence}

A Campbell Review of 66 studies covering 1,092,120 children aged 6 months to 16 years from 23 low and middle-income countries found that:

- Mass deworming for soil-transmitted helminthes probably has little to no effect on weight, height, school attendance, cognition measured by short-term attention, or mortality. There are no data on short-term quality of life and little evidence of adverse effects.

- Mass deworming for schistosomiasis alone may slightly increase weight but probably has little to no effect on height and cognition.

- The evidence does not support indirect benefits for untreated children from being exposed to treated children.

\section{Method}

The evidence summary used the methodology prescribed in
Supporting Policy-relevant Reviews and Trials (SUPPORT) summaries format. ${ }^{1}$ A SUPPORT summary aims to summarise the best and most relevant evidence from systematic reviews of health systems interventions relevant to low- and middle-income countries (LMIC). The objective of such a summary is to extract relevant information from systematic reviews, evaluate the information, and present it in a userfriendly manner so that decision-makers can review the evidence quickly and use it for decision making in their own context.

\subsection{Review on which this evidence summary is based}

Welch VA, Awasthi S, Cumberbatch C, Fletcher R, McGowan J, Merritt K, Krishnaratne S, Sohani S, Tugwell P, Wells GA. Deworming and adjuvant interventions for improving the developmental health and well-being of children in low-and middle-income countries. Campbell Systematic Reviews. 2016 Sep 27; 12. DOI: 10.4073/csr.2016. ${ }^{2}$ An abridged version of the review was later published in Lancet Global Health. ${ }^{3}$

\footnotetext{
* Corresponding author. Campbell Collaboration, New Delhi, India.

E-mail addresses: djohn1976@gmail.com (D. John), annsissac@gmail.com (A. Issac).
} 
Table 1

Summary of systematic review.

\begin{tabular}{|c|c|}
\hline & What did the review authors search for? \\
\hline Types of studies & $\begin{array}{l}\text { Randomized trials, quasi-randomized trials, controlled before after } \\
\text { studies, interrupted time series and quasi-experimental studies that } \\
\text { used statistical methods of analysis to match participants with non- } \\
\text { participants, or statistical methods to account for confounding and } \\
\text { sample selection bias. } \\
\text { Studies that measure worm burden, worm prevalence alone, } \\
\text { albendazole (or equivalent) vs placebo (as this was covered in } \\
\text { previous review }{ }^{6} \text { ), and albendazole }+ \text { vs. placebo }+x \text { (i.e. if the co- } \\
\text { intervention is given to both groups, since this was also included in } \\
\text { the previous review }{ }^{6} \text { ) }\end{array}$ \\
\hline Settings & $\begin{array}{l}\text { Communities (drugs could be administered in schools, health } \\
\text { facilities or via community outreach) }\end{array}$ \\
\hline Participants & $\begin{array}{l}\text { Children aged } 6 \text { months to } 16 \text { years in worm endemic areas in low } \\
\text { and middle-income countries }\end{array}$ \\
\hline Interventions & $\begin{array}{l}\text { Mass drug administration (any licensed drugs) or targeted } \\
\text { chemoprevention (as per WHO guidelines) for treating soil- } \\
\text { transmitted helminthes and schistosomiasis versus placebo or no } \\
\text { treatment. Also included studies of co-interventions (hygiene } \\
\text { promotion and education, sanitation improvements, micronutrients } \\
\text { or feeding programmes) to both intervention and control group. }\end{array}$ \\
\hline
\end{tabular}

What did the review find?

55 studies reported in 75 articles met the inclusion criteria. 46 were RCTs, five CBAs and four long-term studies. The included trials were conducted in 23 countries: India (12 trials), Kenya (5 trials), South Africa (4 trials), 3 each in Bangladesh, Tanzania, Vietnam, 2 each in Haiti, Indonesia, Zaire, and 1 each in Benin, Botswana, Brazil, Cameroon, China, Guatemala, Malaysia, Papua New Guinea, Senegal, Sierra Leone, Sri Lanka, Uganda, Nigeria and 1 multi-country (China, Philippines, Kenya).

The median study duration of RCTS and CBAs was 12 months.

22 trials recruited children from schools, 11 trials from home or community, and 13 trials from health facilities.

The trials primarily included children less than 16 years of age; the median age was 6.5 years.

21 trials had Albendazole $400 \mathrm{mg}$ twice a year compared to placebo or untreated control, four trials co-administered praziquantel for schistosomiasis whereas one RCT assessed mass deworming for schistosomiasis alone.

Placebo was the most common comparator (33 trials), followed by 'no treatment' (10 trials). An intervention was given to both treatment and control arms in eight trials.

21 trials had co-interventions which included iron (9 trials), vitamin A (5 trials), multiple micronutrient fortified biscuits or soup ( 3 trials), unfortified food (5 trials), anti-giardial ( 2 trials) and intermittent presumptive treatment for malaria ( 1 trial). Weight or weight for age was reported by 21 trials, body mass index in five trials, mid-upper arm circumference in 11 trials, triceps skinfold in 7 trials, and height or height for age in 25 trials. 17 trials reported haemoglobin. The proportion stunted was reported in 7 trials, cognition in 9 trials, school performance in 8 trials, school attendance in 7 trials and adverse effects in 5 trials. While only 2 trials reported co-morbidities such as malaria. on test scores); (iii) Cognition (memory, concentration, language development or concept formation); (iv) Well-being: physical (energy, fatigue or fitness levels), emotional or social functioning; patient satisfaction; and (v) Adverse events due to interventions Secondary outcomes: (i) Micronutrient status; (ii) Haematology (haemoglobin, plasma ferritin, transferrin, zinc, serum retinol); (iii) Co-morbidities; (iv) STH and schistosomal prevalence and intensities; (v) Helminth-related morbidities; (vi) any other relevant outcomes relating to health or education (sanitation, hygiene); (vii) Costs and resource use; (viii) Measures of health equity; and (ix) Labour market outcomes

Date of the last search: January 14, 2016

Funding sources: Canadian Institutes of Health Research and the WHO

Limitations: None detected. This review followed standard Campbell review protocol. The review authors assessed the overall quality of the evidence for the pre-selected outcomes considered important to decision-making using the GRADE approach. The review did not exclude studies based on risk of bias.

What were the effects of deworming on the main outcomes sought in the review?

-Mass deworming for soil-transmitted helminthes probably has little to no effect on weight, height, school attendance, cognition measured by short-term attention, or mortality. There are no data on short-term quality of life and little evidence of adverse effects. -Mass deworming for schistosomiasis alone may slightly increase weight but probably has little to no effect on height and cognition. The evidence does not support indirect benefits for untreated children from being exposed to treated children.

-Marginal improvement in hemoglobin concentration was found after mass deworming, especially the combination of STH treatment and praziquantel.

$\cdot 1$ moderate quality long term study showed an increase in economic productivity $(1.5 \mathrm{~h}$ more per week, $95 \% \mathrm{CI}:-0.46$ to 3.62$)$ and increase in educational enrollment $(0.29$ years, $95 \%$ CI: $0.01,0.58) 10$ years later of mass deworming and hygiene promotion. But, it is uncertain whether these effects are due to the deworming or the combined hygiene intervention.

-Findings are consistent for various groups of the population by age, gender, worm prevalence, baseline nutritional status, compliance, impact on worms, infection intensity, types of worms, risk of bias, and study characteristics.

-Deworming for children who screened positive for schistosomiasis or soil-transmitted helminthes results in larger gains in weight compared to control but no difference in effect on height, cognition or school attendance.

- Also, one low to moderate quality study showed long-term benefit on school enrolment of sanitation improvement combined with screening and treating people for hookworm infection.

What were the conclusions of the review?

What were the assessments of the overall quality of the evidence?

Did the results and conclusions of the review differ from other reviews on this topic?

The authors concluded that "mass deworming is probably not effective on average at improving weight, height, cognition, school attendance or mortality at a population level, even in areas with very high intensity and prevalence of infection or when combined with food or micronutrients".

The overall evidence quality was graded moderate to high using the GRADE approach for the primary outcomes in the review. However, the long-term outcomes were downgraded due to risk of bias, loss to follow-up and indirectness of the intervention. Also, evidence on mass deworming for schistosomiasis was rated low quality due to limited evidence.

The result of this review differed from 3 prior reviews ${ }^{7-9}$ that found significant effects on mass deworming on weight, height or cognition. The current review found little to no effect on growth partly due the publication of additional eight trials since the reviews published in 2008 , and all reporting no difference in weight and height between deworming and placebo.

The results from this review also differed from another global evidence ${ }^{10}$ that found larger effects in higher prevalence areas. The main reason being that the current review included additional ${ }^{10}$ studies in the meta-analyses. The analysis of this full sample did not find a relationship between effect size for weight and prevalence of any type of worm in weight least squares regression.

Another meta-evaluation by J-PAL (2012) ${ }^{11}$ that included 4 studies using data as part of the Primary School Deworming Project (PSDP) in Kenya, found a positive effect of deworming on school attendance and health. The current review included additional six studies that measured school attendance and the evidence was rated low due to concerns about indirect effects (due to presence of hygiene promotion in treatment schools) and risk of bias to lack of blinding of participants, teachers and field workers collecting data.

The findings of the current review are consistent with a Cochrane review on the same topic.6 However, this review provided new evidence 


\begin{tabular}{|c|c|}
\hline & What did the review authors search for? \\
\hline \multirow{7}{*}{$\begin{array}{l}\text { What are the implications of the } \\
\text { review for public health? }\end{array}$} & $\begin{array}{l}\text { not assessed in the Cochrane review by comparing different STH drugs, combination of STH and schistosomiasis anthelminthics or } \\
\text { combinations of micronutrients, nutrition or hygiene promotion. }\end{array}$ \\
\hline & $\begin{array}{l}\text { The results in this review found marginal improvement in haemoglobin concentration after mass deworming, especially the combination of } \\
\text { STH treatment and praziquantel, and are consistent as reported with other reviews. }{ }^{12,13}\end{array}$ \\
\hline & $\begin{array}{l}\text { The current review findings are congruent with previous review, }{ }^{14} \text { that deworming medications had no effect on learning impact (language } \\
\text { or reading, mathematics, or a composite). }\end{array}$ \\
\hline & $\begin{array}{l}\text { The different conclusions of current review are due to inclusion of more studies and adoption of a strict criterion for the certainty of } \\
\text { evidence. }\end{array}$ \\
\hline & $\begin{array}{l}\text { This review highlighted that mass deworming has probably little to no effect on improving child health and other welfare outcomes. Also, } \\
\text { there is no data on short-term quality of life. The evidence is insufficient to interpret the subgroup analyses of age, nutritional status, sex and } \\
\text { deworming prevalence. }\end{array}$ \\
\hline & $\begin{array}{l}\text { Deworming for schistosomiasis alone may have a small positive impact on weight gain, however the cost effectiveness of such interventions } \\
\text { need to be considered before implementing massive programmes in resource-poor settings. }\end{array}$ \\
\hline & $\begin{array}{l}\text { Additional policy options to address the basic determinants of worm infestations need to be explored to improve child health and nutrition in } \\
\text { worm-endemic areas. }\end{array}$ \\
\hline
\end{tabular}

RCT: Randomized Controlled Trials.

CBA: Controlled Before and After WHO: World Health Organization.

CI: Confidence Interval.

This was one among the 4 reviews considered for developing the World Health Organization guideline on preventive chemotherapy to control soil-transmitted helminth infections in at-risk population groups. ${ }^{4}$ Also, the review was highlighted by GiveWell, which is a charity that uses evidence base to make funding suggestions for donors. ${ }^{5}$

\section{Results}

\subsection{Why is this question important?}

- Soil-transmitted helminthiasis and schistosomiasis, considered among the neglected tropical diseases by the World Health Organization, affect more than a third of the world's population, with varying intensity of infection.

- There is debate about the effectiveness and cost-effectiveness of mass deworming of children as a strategy to improve child health in endemic areas.

1. What did the systematic review seek and what did they find?

Review objective: To evaluate the effects of mass deworming for soil transmitted helminthes, schistosomiasis or both (depending on endemicity) in conjunction with other co-interventions (such as hygiene promotion, school feeding and micronutrients) in children (6 months-16 years) in low and middle-income countries on growth, educational status, cognition, school attendance, well-being and adverse effects (see Tables 1-4).

\section{Conclusion}

The relevance for the review findings in low and middle-income countries are summarised in Table 5 .

\section{Source of funding}

None.

\section{Conflicts of interest}

The lead author is a staff of Campbell Collaboration at its New Delhi office. The evidence summary is based on a review that is published in Campbell library.

Table 2

Mass deworming with albendazole $400 \mathrm{mg}$ twice per year compared to control for children in STH endemic areas.

\begin{tabular}{|c|c|c|c|}
\hline Outcomes & Impact & $\begin{array}{l}\text { Number of participants } \\
\text { (studies) }\end{array}$ & Overall quality of evidence \\
\hline Weight gain $(\mathrm{Kg})$ & There is probably little or no difference in weight gain & 35430 (11 RCTs) & $\begin{array}{l}\text { Moderate (downgraded due to } \\
\text { inconsistency) }\end{array}$ \\
\hline Height gain $(\mathrm{cm})$ & There is probably little or no difference in height gain & 6839 (9 RCTs) & $\begin{array}{l}\text { Moderate (downgraded due to } \\
\text { inconsistency) }\end{array}$ \\
\hline $\begin{array}{l}\text { Cognitive processing (different } \\
\text { scales) }\end{array}$ & $\begin{array}{l}\text { There is probably little or no difference in cognitive } \\
\text { processing }\end{array}$ & 4078 (3 RCTs) & High \\
\hline School attendance (\%) & There is probably little or no difference in attendance & $>30,000$ (7 RCTs) & $\begin{array}{l}\text { Moderate (downgraded due to } \\
\text { inconsistency) }\end{array}$ \\
\hline Proportion stunted & $\begin{array}{l}\text { There is probably little or no difference in proportion } \\
\text { stunted }\end{array}$ & 4286 (4 RCTs) & High \\
\hline Mortality & There is probably little or no difference in mortality & Over one million (6 RCTs) & High \\
\hline Long term hours worked per week & $\begin{array}{l}\text { It is uncertain whether mass deworming improves hours } \\
\text { worked after } 10 \text { years }\end{array}$ & 5084 (1 RCT) & $\begin{array}{l}\text { Very low (due to risk of bias and } \\
\text { indirectness) }\end{array}$ \\
\hline
\end{tabular}

Population: Children in STH endemic areas.

Setting: Low and middle-income countries.

Intervention: Mass de-worming with albendazole $400 \mathrm{mg}$ twice per year.

Comparison: Control.

STH: Soil-transmitted Helminthiasis.

RCT: Randomized Controlled Trials. 
Table 3

Mass deworming with albendazole $400 \mathrm{mg}$ twice per year + Praziquantel $40 \mathrm{mg} / \mathrm{kg}$ once per year compared to control for children in STH and schistosomiasis endemic areas.

\begin{tabular}{|c|c|c|c|}
\hline Outcomes & Impact & $\begin{array}{l}\text { Number of participants } \\
\text { (studies) }\end{array}$ & Overall quality of evidence \\
\hline Weight gain (Kg) & $\begin{array}{l}\text { There may be little or no difference in weight } \\
\text { gain }\end{array}$ & 438 (2 RCTs) & $\begin{array}{l}\text { Low (downgraded due to risk of bias and } \\
\text { imprecision) }\end{array}$ \\
\hline Height gain $(\mathrm{cm})$ & There may be little or no difference in height gain & 438 (2 RCTs) & $\begin{array}{l}\text { Low (downgraded due to risk of bias and } \\
\text { imprecision) }\end{array}$ \\
\hline Cognitive processing (different scales) & $\begin{array}{l}\text { There is little or no difference in cognitive } \\
\text { processing }\end{array}$ & 4078 (3 RCTs) & High \\
\hline School attendance (\%) & There may be little or no difference in attendance & 4718 (1 RCT) & $\begin{array}{l}\text { Low (downgraded due to risk of bias and } \\
\text { imprecision) }\end{array}$ \\
\hline Proportion stunted & $\begin{array}{l}\text { There may be little or no difference in proportion } \\
\text { stunted }\end{array}$ & 263 (1 RCT) & Low (downgraded due to imprecision) \\
\hline Mortality & There is little or no difference in mortality & Over one million (6 RCTs) & $\begin{array}{l}\text { Moderate (downgraded due to } \\
\text { indirectness) }\end{array}$ \\
\hline $\begin{array}{l}\text { Economic productivity, as measured by long term } \\
\text { hours worked per week }\end{array}$ & $\begin{array}{l}\text { It is uncertain whether mass deworming } \\
\text { improves hours worked after } 10 \text { years }\end{array}$ & 5084 (1 RCT) & $\begin{array}{l}\text { Very low (due to risk of bias and } \\
\text { indirectness) }\end{array}$ \\
\hline
\end{tabular}

Population: Children in STH and schistosomiasis endemic areas.

Setting: Low and middle-income countries.

Intervention: Mass de-worming with albendazole $400 \mathrm{mg}$ twice per year + praziquantel $40 \mathrm{mg} / \mathrm{kg}$ once per year.

Comparison: Control.

STH: Soil-transmitted Helminthiasis.

RCT: Randomized Controlled Trials.

Table 4

Mass deworming with praziquantel $40 \mathrm{mg} / \mathrm{kg}$ once per year compared to control for in children in schistosomiasis endemic areas.

\begin{tabular}{|c|c|c|c|}
\hline Outcomes & Impact & $\begin{array}{l}\text { Number of participants } \\
\text { (studies) }\end{array}$ & Overall quality of evidence \\
\hline Weight gain $(\mathrm{Kg})$ & Mass deworming may increase weight slightly & 182 (1 study) & $\begin{array}{l}\text { Low (downgraded due to risk of bias and } \\
\text { imprecision) }\end{array}$ \\
\hline Height gain $(\mathrm{cm})$ & There is probably little or no difference in height gain & 182 (1 study) & $\begin{array}{l}\text { Low (downgraded due to risk of bias and } \\
\text { imprecision) }\end{array}$ \\
\hline $\begin{array}{l}\text { Long term hours worked per } \\
\text { week }\end{array}$ & $\begin{array}{l}\text { It is uncertain whether mass deworming improves hours } \\
\text { worked after } 10 \text { years }\end{array}$ & $>80,000$ ( 1 study) & Very low (downgraded for study limitations) \\
\hline
\end{tabular}

Population: Children in schistosomiasis endemic areas.

Setting: Low and middle-income countries.

Intervention: Mass de-worming with praziquantel $40 \mathrm{mg} / \mathrm{kg}$ once per year.

Comparison: Control.

Table 5

Relevance of the review for low and middle-income countries.

\begin{tabular}{|c|c|}
\hline Findings & Interpretations \\
\hline
\end{tabular}

\section{APPLICABILITY}

All the included studies were conducted in low and middle-income countries, and covered 23 countries across Asia, Africa and Latin America.

11 studies described all participants as belonging to low-income households Sanitation and/or hygiene practices were described as poor, in 17 studies

Most common intervention was albendazole, and co-interventions were provided in 21 studies.

Methods of administration (field workers, school staff, study staff, health workers and home) varied across studies

Common comparator was placebo. Long term studies had control groups receiving deworming at end of the study period or on average received 2.41 years less deworming.

Majority of the studies $(n=36)$ reported high prevalence ( $>50$ percent worm prevalence), followed by 7 studies reporting moderate prevalence ( $20-50$ percent), and 6 with low prevalence $(<20$ percent).

23 studies, reporting impact on worms for mass deworming of children programmes, had considerable variability in effectiveness at reducing worm prevalence at end of the study periods

EQUITY

Only 2 studies reported conducting within-study analysis across income-level and were rated as very low certainty evidence.

13 studies were conducted in very low income settings, but the results for weight, height and school attendance showed little to no effect of mass deworming.
- The findings of the review are applicable to low and middle-income countries considering the wide geographical coverage of included studies (India, Kenya, South Africa, Bangladesh, Tanzania, Vietnam, Haiti, Indonesia, Zaire, Benin, Botswana, Brazil, Cameroon, China, Guatemala, Malaysia, Papua New Guinea, Philippines, Senegal, Sierra Leone, Sri Lanka, Uganda and Nigeria).
- When restricted to very poor settings, there is little evidence to suggest that deworming is pro-poor since the effects on weight, height, and attendance were found to be small in these studies conducted predominantly in low-income settings. 
Table 5 (continued)

\begin{tabular}{|c|c|}
\hline Findings & Interpretations \\
\hline \multicolumn{2}{|l|}{ ECONOMIC CONSIDERATIONS } \\
\hline $\begin{array}{l}8 \text { studies were included with some type of economic evaluation; however, no quality } \\
\text { appraisal was conducted. }\end{array}$ & $\begin{array}{l}\text { Costs and incremental cost-effectiveness ratio per unit outcome need to be converted to } \\
\text { base year calculations with uniform currency. This is important for comparison of costs } \\
\text { across countries and for cost data collected across different years. } \\
\text { Unit costs (e.g. costs of deworming drugs) and resource costs (e.g. costs of } \\
\text { administration in schools) may vary across jurisdictions. It is important to capture these } \\
\text { variations in order to present generalizability of study findings. }\end{array}$ \\
\hline \multicolumn{2}{|l|}{ MONITORING \& EVALUATION } \\
\hline $\begin{array}{l}\text { No relationship was found between prevalence of worms or impact on worms and the } \\
\text { effect on weight gain, height gain or attendance, even when restricted to studies } \\
\text { with high intensity of infection. } \\
\text { No relationship was found between age of children and treatment effect. There } \\
\text { were conflicting results with subgroup analyses within studies on age and } \\
\text { underweight. } \\
\text { Variations in deworming effects could not be explained by baseline nutritional } \\
\text { status, baseline worm prevalence or treatment success on reducing worm burden. }\end{array}$ & $\begin{array}{l}\text { While considering the impacts of a programme it is important to consider process } \\
\text { evaluation components as well to identify facilitators and barrier factors influencing } \\
\text { implementation. } \\
\text { It is also important to identify costs of implementation along with input costs. }\end{array}$ \\
\hline
\end{tabular}

\section{Acknowledgements}

The authors thank Dr. Vivian Welch, Editor-in-Chief, Campbell Collaboration, and the lead author of the Campbell review on deworming, for review comments during the finalisation of the manuscript.

\section{References}

1. Rosenbaum SE, Genton C, Wiysonge CS, et al. Evidence summaries tailored to health policy-makers in low- and middle-income countries. Bull World Health Organ. 2011;89:54-61.

2. Welch VA, Awasthi S, Cumberbatch C, et al. Deworming and adjuvant interventions for improving the developmental health and well-being of children in low-and middle-income countries. Campbell Syst. Rev. 2016 Sep 27:12. https://doi.org/10. 4073/csr.2016.7.

3. Welch VA, Ghogomu E, Hossain A, et al. Mass deworming to improve developmental health and wellbeing of children in low-income and middle-income countries: a systematic review and network meta-analysis. Lancet Global Health. 2017 Jan 1;5(1): $40-50$.

4. World Health Organization. Guideline: Preventive Chemotherapy to Control Soil-transmitted Helminth Infections in at-Risk Population Groups. 2017; 2017http://www.who. int/nutrition/publications/guidelines/deworming/en/.

5. Roodman D. How Thin the Reed? Generalizing from "Worms at Work". The GiveWell

Blog; January 2017https://blog.givewell.org/2017/01/04/how-thin-the-reedgeneralizing-from-worms-at-work/.

6. Taylor-Robinson DC, Maayan N, Soares-Weiser K, Donegan S, Garner P. Deworming drugs for soil-transmitted intestinal worms in children: effects on nutritional indicators, haemoglobin and school performance. Cochrane Database Syst Rev. 2015;7:CD000371.

7. Albonico M, Allen H, Chitsulo L, Engels D, Gabrielli Albis-Francesco, Savioli L. Controlling soil-transmitted helminthiasis in pre-school age children through preventive chemotherapy. PLoS Neglected Trop Dis. 2008;2(3):e126.

8. de Silva NR, Brooker S, Hotez PJ, Montresor A, Engels D, Savioli L. Soil-transmitted helminth infections: updating the global picture. Trends Parasitol. 2003;19:547-551.

9. Hall A, Hewitt G, Tuffrey V, De Silva N. A review and meta-analysis of the impact of intestinal worms on child growth and nutrition. Matern Child Nutr. 2008;4:118-236.

10. Croke K, Hicks JH, Hsu E, Kremer M, Miguel E. Does mass deworming affect child nutrition? Meta-analysis, cost-effectiveness, and statistical power. NBER Working Paper. 2016:22382https://doi.org/10.3386/w22382.

11. J-PAL Policy Bulletin. Deworming: A Best Buy for Development. Cambridge, MA: Abdul Latif Jameel Poverty Action Lab; 2012.

12. Smith JL, Brooker S. Impact of hookworm infection and deworming on anaemia in non-pregnant populations: a systematic review. Trop Med Int Health. 2010;15(7):776-795.

13. Gulani A, Nagpal J, Osmond C, Sachdev HPS. Effect of administration of intestinal anthelmintic drugs on haemoglobin: a systematic review of randomised controlled trials. BMJ. 2007;334(7603):1095.

14. McEwan PJ. Improving learning in primary schools of developing countries: a metaanalysis of randomized experiments. Rev Educ Res. 2015;85(3):353-394. 